\title{
Qualidade agronômica da cenoura sob níveis de salinidade da água de irrigação e adubação orgânica
}

Propôs-se com a presente pesquisa avaliar a qualidade agronômica da cenoura sob níveis de salinidade da água de irrigação e tipos de adubação orgânica por meio da análise multivariada. O experimento foi desenvolvido em casa de vegetação da Universidade Federal de Campina Grande (UFCG). Os tratamentos foram cinco níveis de salinidade da água ( $\mathrm{S} 1: 0,7 ; \mathrm{S} 2: 1,4 ; \mathrm{S} 3: 2,1 ; \mathrm{S} 4: 2,8 ; \mathrm{S} 5: 3,5 \mathrm{dS} \mathrm{m}-1$ ) e dois tipos de adubação (solo sem adubação orgânica e solo com adubação orgânicahúmus de minhoca). 0 delineamento foi em blocos casualizados, com 3 repetições. Aos 90 dias após a emergência foram avaliados altura de plantas, número de folhas, área foliar, diâmetro inferior e superior da raiz, massa fresca e seca da raiz e teor de sólidos totais ( $\left.{ }^{\circ} B r i x\right)$. 0 uso das técnicas de multivariadas mostrou-se uma ferramenta útil no estudo entre as correlações dos diferentes níveis de salinidade da água de irrigação e os tipos de adubação, a fim de verificar o efeito na qualidade agronômica de cenoura. O nível de salinidade de $0,7 \mathrm{dSm}-1$ associada a adubação com húmus de minhoca favoreceu a qualidade agronômica das raízes de cenoura. $O$ efeito da salinidade nos níveis elevados foi atenuado pela adubação orgânica.

Palavras-chave: Daucus Carota L; Estresse Salino; Húmus de Minhoca; Componentes Principais.

\section{Agronomic quality of the carrot under irrigation water salinity levels and organic fertilization}

This research aimed to evaluate the to evaluate the agronomic quality of the carrot under irrigation water salinity levels and types of organic fertilization through multivariate analysis. The experiment was carried out in a greenhouse at the Federal University of Campina Grande (UFCG). The treatments were five salinity levels (S1: 0.7, S2: 1.4, S3: 2.1, S4: 2.8, S5: $3.5 \mathrm{dS} \mathrm{m-1)} \mathrm{and} \mathrm{two} \mathrm{types} \mathrm{of} \mathrm{fertilization} \mathrm{(soil} \mathrm{without} \mathrm{organic} \mathrm{fertilization} \mathrm{and} \mathrm{soil} \mathrm{with} \mathrm{organic} \mathrm{fertilization} \mathrm{-} \mathrm{earthworm}$ humus). The experimental design was in randomized blocks with 3 replicates. At 90 days after emergence were evaluated the length plant height, leaf number, leaf area, lower and upper root diameter, fresh and dry root mass and total solids content ( ${ }^{\circ}$ Brix). The use of multivariate techniques proved to be a useful tool in the study between correlations of different irrigation water salinity levels and types of fertilization in order to verify the effect on the agronomic quality of carrot. The salinity level of $0.7 \mathrm{dSm}-1$ associated with fertilization with earthworm humus favored the agronomic quality of the carrot roots. The effect of salinity on high levels was attenuated by organic fertilization.

Keywords: Daucus Carota L; Saline Stress; Earthworm Humus; Principal Component.

Topic: Engenharia Agrícola

Reviewed anonymously in the process of blind peer
Received: $12 / 02 / 2019$

Approved: 28/03/2019
Barbara Davis Brito dos Santos

Universidade Federal de Campina Grande, Brasi http://lattes.cnpq.br/4374064087207806

barbara.brito90@hotmail.com

Patrícia Ferreira da Silva (iD

Universidade Federal de Campina Grande, Brasil http://orcid.org/0000-0002-4580-2336

patrycyafs@yahoo.com.br

Rigoberto Moreira de Matos (iD)

Universidade Federal de Campina Grande, Brasil http://lattes.cnpq.br/9976807429777592 http://orcid.org/0000-0003-3455-9876

rigobertomoreira@gmail.com

\author{
Vitoria Ediclécia Borges (iD) \\ Universidade Federal de Campina Grande, Brasil \\ http://lattes.cnpq.br/9270575826636578 \\ http://orcid.org/0000-0001-6279-350X \\ edicleciaborges@gmail.com \\ Jose Dantas Neto id \\ Universidade Federal de Campina Grande, Brasil \\ http://lattes.cnpq.br/9137226205129315 \\ http://orcid.org/0000-0003-0798-6717 \\ zedantas1955@gmail.com \\ Vera Lucia Antunes de Lima (iD \\ Universidade Federal de Campina Grande, Brasil \\ http://lattes.cnpq.br/5379077061489077 \\ http://orcid.org/0000-0001-7495-6935 \\ antuneslima@gmail.com
}

Referencing this:

SANTOS, B. D. B.; SILVA, P. F.; MATOS, R. M.; BORGES, V. E.; NETO, J. D.; LIMA, V. L. A.. Qualidade agronômica da cenoura sob níveis de salinidade da água de irrigação e adubação orgânica. Revista Ibero Americana de Ciências Ambientais, v.10, n.2, p.1-9, 2019. DOI: http://doi.org/10.6008/CBPC2179-6858.2019.002.0001 


\section{INTRODUÇÃO}

A cenoura (Daucus carota L.) e uma cultura bienal, dicotiledônea herbácea e pertencente à família Apiaceae (Umbeliferae), gênero Daucus, com grande expressão econômica, devido ao elevado consumo em todo o mundo. No Brasil, a cultura da cenoura desempenha importante papel social, por gerar emprego e renda em todas as etapas de produção da raiz (NETO et al., 2014). O consumidor tem preferência por cenouras com qualidade agronômica diferenciada com raízes bem desenvolvidas, lisas, cilíndricas, sem a presença de raízes laterais ou secundarias, uniformes, com comprimento entre 20 a $25 \mathrm{~cm}$ e com diâmetro de 3 a $4 \mathrm{~cm}$ (TEIXEIRA et al., 2011).

A raiz é um alimento com elevado valor nutritivo pois, contém alto teor de $\beta$-caroteno precursor da vitamina A, contendo também, carboidratos, cálcio, fósforo, ferro, magnésio, e sais minerais sendo amplamente consumida no Brasil (KRÄHMER et al., 2016). Além das raízes, os talos e folhas são fonte de proteínas, carboidratos, lipídeos, polifenóis e antioxidantes, que podem utilizados para acrescentar nutrientes em diferentes receitas (STORCK et al., 2013).

A qualidade agronômica dessa raiz é influenciada por diversos fatores, dentre os quais a salinidade é um fator limitante para a produção agrícola, devido aos efeitos osmóticos, estresse oxidativo e toxicidade, causando alterações morfológicas, estruturais e metabólicas (Mao et al., 2016). Ocorrem alterações nas trocas gasosas devido a diminuição no potencial osmótico do solo da solução do solo (DIAS et al., 2016). Em resposta a condição de estresse salino há diminuição da condutância estomática e transpiração para minimizar a perda de água evitando a desidratação. A fotossíntese também é afetada com as concentrações elevadas $\mathrm{Na}+$ e/ou $\mathrm{Cl}$ - no interior dos nos cloroplastos (BERTOLLI et al., 2015). A cenoura é sensíveis a sais, quando a água de irrigação com condutividade elétrica de sais é de no máximo de é de até $0,7 \mathrm{dS} \mathrm{m}^{-1}$ e do extrato saturado até $1,0 \mathrm{dS} \mathrm{m}^{-1}$ a 25 ํ C não há redução na produção, entanto, com o aumento da salinidade, ocorre redução da produtividade (AYRES et al., 1991).

Nesse sentido, a análise multivariada é utilizada para explicar a variância de um grande conjunto de dados de variáveis interligadas com um pequeno conjunto de variáveis independentes. A utilização da análise multivariada no estudo da qualidade agronômica da cenoura visa reduzir a representação dimensional dos dados, organizando-os em uma estrutura que facilita a visualização de todo o conjunto de dados permitindo a identificação das variáveis que mais contribuem para a qualidade agronômica final da raiz (HAIR et al., 2009). Diante disso, o objetivo do trabalho foi avaliar o crescimento, características morfológicas e produtividade da cenoura sob diferentes níveis de salinidade da água de irrigação e tipos de adubação orgânica por meio da análise multivariada.

\section{MATERIAIS E MÉTODOS}

O experimento foi desenvolvido em casa de vegetação em área pertencente à Universidade Federal de Campina Grande (UFCG), Campus Campina Grande, localizado nas coordenadas geográficas $7^{\circ} 12^{\prime} 88^{\prime \prime}$ de latitude sul e $35^{\circ} 54^{\prime} 40^{\prime \prime}$ de longitude oeste e altitude de $532 \mathrm{~m}$, no período de agosto a outubro de 2016 . A 
estufa possuí $15 \mathrm{~m}$ de comprimento, $10 \mathrm{~m}$ de largura e $3 \mathrm{~m}$ de pé-direito, coberta com telha de fibra de vidro e laterais com tela tipo sombrite. Os dados de temperatura e umidade relativa do ar durante o período experimental, desde a semeadura até a colheita, correspondendo a 90 dias, foram coletados diariamente em termohigrometro instalado no inferior da estufa (Figura 1A e B).

A

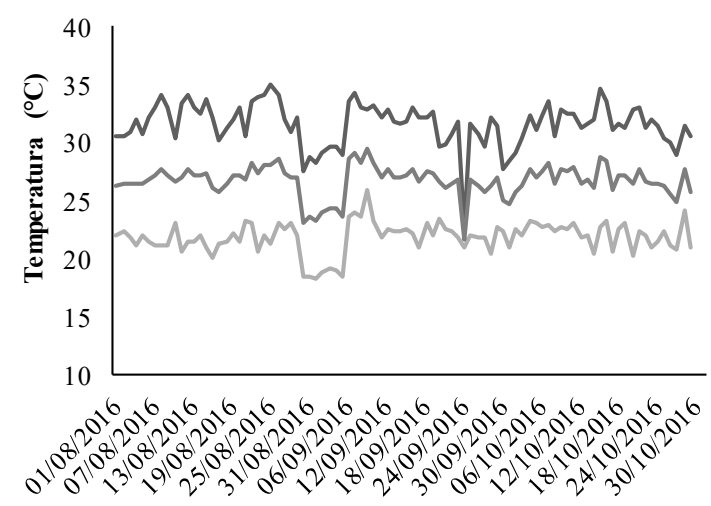

Dias após o transplantio

—Tmáx Tmín Tméd
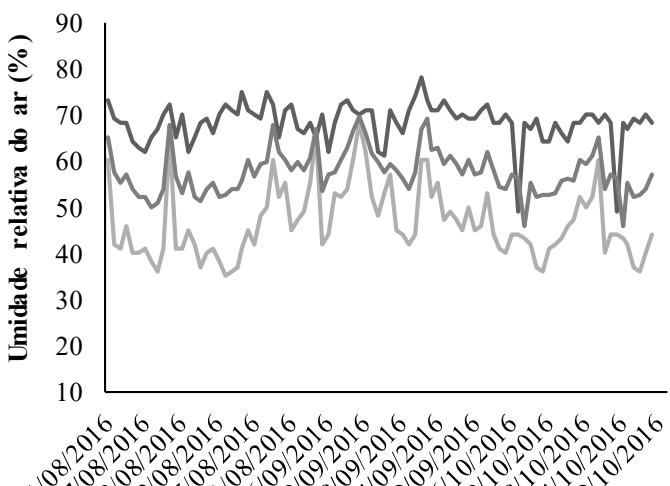

1010 क

Dias após o transplantio

—Umáx Umín Tméd

Figura 1: Temperatura máxima, média e mínima (1A) e Umidade relativa do ar máxima, média e mínima (1B), durante o período experimental.

O solo utilizado na pesquisa foi classificado como de textura franco-arenosa (EMBRAPA, 2013) e as características físicas, químicas e hídricas na profundidade de 0-20 cm, encontram-se na Tabela 1. As características químicas e de fertilidade da análise do húmus de minhoca utilizado no experimento encontrase na Tabela 2.

Tabela 1: Características químicas do solo utilizado no experimento na profundidade de $0,0-20,0 \mathrm{~cm}$.

\begin{tabular}{|c|c|c|c|c|c|c|c|}
\hline \multirow{2}{*}{$\begin{array}{l}\mathrm{pH} \\
\mathrm{H}_{2} \mathrm{O} \\
\end{array}$} & \multirow{2}{*}{$\begin{array}{l}\mathrm{P} \\
\left(\mathrm{mmol}_{\mathrm{c}} \mathrm{dm}^{-3}\right)\end{array}$} & \multirow[t]{2}{*}{ M.O } & K & $\mathrm{Ca}$ & $\mathrm{Mg}$ & $\mathrm{Al}$ & $\mathrm{T}$ \\
\hline & & & \multicolumn{5}{|c|}{$\mathrm{mmol}_{\mathrm{c}} \mathrm{dm}^{3}$} \\
\hline 5,9 & 1,43 & 0,65 & 0,28 & 1,90 & 0,66 & 0,87 & 4,86 \\
\hline
\end{tabular}

Tabela 2: Característica do fertilizante orgânico (húmus de minhoca) usado no experimento.

\begin{tabular}{|c|c|c|c|c|c|c|c|c|c|c|c|}
\hline $\mathrm{pH}$ & MO & $P$ & $\mathrm{~K}$ & $\mathrm{Na}$ & $\mathrm{Ca}$ & $\mathrm{Mg}$ & $\mathrm{Al}$ & SB & CTC & V & $\mathrm{M}$ \\
\hline \multicolumn{5}{|c|}{$\mathrm{g} / \mathrm{kg}$} & \multicolumn{3}{|c|}{$\mathrm{mg} \mathrm{dm}^{-3}$} & \multicolumn{2}{|c|}{$-\mathrm{Cmol}_{\mathrm{c}} \mathrm{dm}^{-3}$-- } & \multicolumn{2}{|l|}{----\%---- } \\
\hline 6,9 & 73,1 & 469,3 & 656,0 & 0,9 & $\begin{array}{l}13,2 \\
\end{array}$ & 1,0 & 0,0 & 18,9 & 20,8 & \begin{tabular}{l|l}
91,2 \\
\end{tabular} & 0,0 \\
\hline
\end{tabular}

${ }^{*} \mathrm{pH}=$ potencial hidrogeniônico, $\mathrm{MO}=$ matéria orgânica, $\mathrm{P}=$ fósforo, $\mathrm{K}=$ potássio, $\mathrm{Na}=$ sódio, $\mathrm{Ca}=\mathrm{cál}$ cio, $\mathrm{Mg}=$ magnésio, $\mathrm{Al}=$ alumínio, $\mathrm{SB}=$ soma de bases, $\mathrm{CTC}=$ capacidade de troca de cátions, $\mathrm{V}=$ saturação por base $\mathrm{m}=$ saturação por alumínio.

O delineamento estatístico adotado foi o de blocos casualizado completos, com três repetições. Os tratamentos foram compostos pela combinação de dois fatores: cinco níveis de salinidade da água de irrigação - $\mathrm{CEa}\left(\mathrm{S} 1=0,6 ; \mathrm{S} 2=1,2 ; \mathrm{S} 3=1,8 ; \mathrm{S} 4=2,4\right.$ e $\mathrm{S} 5=3,0 \mathrm{dS} \mathrm{m}^{-1}$ ) e dois tipos de adubação ( $\mathrm{A} 1$ - solo sem adubação orgânica e A2 - Solo com adubação orgânica -húmus de minhoca).

Os tratamentos foram dispostos em 30 vasos, sendo cada parcela constituída por dois vasos de $10 \mathrm{~L}$ espaçados de 0,5 m entre vasos e 0,9 m entre linhas dos vasos. Os vasos possuíam orifícios na parte inferior, contendo uma camada de $1 \mathrm{~cm}$ de brita № 1, recoberta com manta geotêxtil para facilitar a drenagem; os vasos foram completados com cerca de $13 \mathrm{~kg}$ de solo. As águas de diferentes concentrações salinas foram 
obtidas a partir da adição de cloreto de sódio $(\mathrm{NaCl})$ a água de abastecimento, conforme a equação 1 proposta por Richards (1954).

$$
\mathrm{C}=640 * \mathrm{CEa}
$$

Eq. 1

Em que: $\mathrm{C}=$ concentração de $\mathrm{NaCl}\left(\mathrm{mg} \mathrm{L}^{-1}\right)$; $\mathrm{CEa}=$ Condutividade elétrica da solução $\left(\mathrm{dS} \mathrm{m}^{-1}\right)$.

A irrigação com água salina foi iniciada após a emergência das plantas, quando estas estavam com 15 dias após a semeadura. A adubação com húmus de minhoca foi na proporção de 2:2, ou seja, $2 \mathrm{~kg}$ de húmus para $2 \mathrm{~kg}$ de solo. Os tratamentos com húmus de minhoca foram distribuídos de forma aleatória nos blocos.

O plantio foi realizado utilizando 4 sementes de cenoura (Daucus carota L), a cultivar utilizada foi a Brasília, uma das mais cultivadas na região por pequenos olericultores dos cinturões verdes próximos a cidade de Campina Grande - PB. As sementes foram colocadas em covas de $1 \mathrm{~cm}$ de profundidade e após 15 da emergência foi efetuado o desbaste, deixando uma planta por vaso. Antes do plantio foi efetuada uma irrigação para elevar a umidade do solo à capacidade de campo.

O manejo da irrigação foi diário sempre no final da tarde, de forma a aplicar água apenas no solo. 0 volume de água drenado foi coletado na manhã do dia seguinte. Pela diferença entre o volume de água aplicado e drenado, estimou-se a evapotranspiração da cultura (consumo), determinado diariamente, assim, o volume de água a ser aplicado foi calculado com base no consumo do dia anterior. A fim de se obterem frações de lixiviação de 0,15 e 0,20, respectivamente, para cada etapa do ciclo da cultura, seguiu-se a equação de Rhoades (1974) (Eq. 2).

$$
V I=\frac{\mathrm{VA}-\mathrm{VD}}{1-F}
$$

Em que: $\mathrm{VI}$ - Volume de água a ser aplicada na irrigação $(\mathrm{mL})$; VA - Volume de água aplicado na irrigação anterior ou no período $(\mathrm{mL})$; VD - Volume de água drenada na irrigação anterior ou no período $(\mathrm{mL})$; FL - Fração de lixiviação $(0,15$ e 0,2).

As irrigações foram de forma manual com proveta graduada para medir as quantidades a serem aplicadas e drenadas diariamente. Avaliou-se a qualidade agronômica das raízes de cenoura aos 90 dias após a emergência das plantas. As plantas de cada unidade experimental foram colhidas separadamente e acondicionadas em sacos de papel previamente identificadas, em seguida foram transportadas para o laboratório de Irrigação e Drenagem (LEID), onde foram analisadas as seguintes variáveis: altura de planta (AP) mensurada do colo da planta até a base da última folha emitida utilizando régua graduada em $\mathrm{cm}$; número de folhas (NF) por planta por meio da contagem direta. A área foliar (AF) foi obtida através da Equação 3, multiplicando o comprimento e a largura da folha pelo fator de correção.

$$
A F=C * L * f
$$

Eq. 3

Em que: AF - Área foliar, em $\mathrm{cm}^{2}$; C - Comprimento da folha, em $\mathrm{cm}$; $\mathrm{L}$ - Largura da folha, em cm; e f - Fator de correção para o rabanete $(0,55)$, adimensional. O diâmetro superior (DSR) e inferior (DIR) da raiz tuberosa, com paquímetro digital; massa fresca (MFR) e seca (MSR) da raiz tuberosa estas foram lavadas e separando, raízes tuberosa da parte aérea sendo 
pesadas separadamente em balança analítica de precisão $(0,01 \mathrm{~g})$ e teor de sólidos solúveis totais ( ${ }^{\circ}$ Brix) determinado com refratômetro digital.

Os dados obtidos foram padronizados, de modo a tornar a média nula e variância unitária. A estrutura multivariada dos resultados foi avaliada por meio da Análise exploratória de Componentes Principais (ACP), condensando-se a quantidade de informação relevante contida no conjunto de dados originais em um menor número de dimensões, resultantes de combinações lineares das variáveis originais geradas a partir dos autovalores mais elevados na matriz de covariância (HAIR et al., 2009).

A análise de agrupamento hierárquico seguiu o mesmo procedimento de padronização e adotou-se a distância euclidiana como medida de similaridade e o método de Ward para ligação das variáveis. Todas as análises estatísticas foram processadas com auxílio do programa computacional STATISTICA versão 7 (STATSOFT, 2004).

\section{RESULTADOS E DISCUSSÃO}

A utilização da análise multivariada permitiu reduzir o espaço multidimensional do conjunto original de variáveis em dois Componentes Principais (CP) com autovalores maiores que a unidade $(\lambda>1,0)$, conforme preconiza o critério de Kaiser para escolha de CPs (Tabela 3). Os dois Componentes escolhidos explicam 82,73\% da variância total, sendo que o primeiro Componente Principal (CP1) retém 67,14\% da variância total acumulada, enquanto que o segundo Componentes (CP2) contribuem com 15,58\% desta variância (Tabela 3).

Tabela 3: Matriz dos componentes: raiz características autovalores $(\Lambda)$, percentual da variância total explicada por cada componente principal $\left(\sigma^{2} \%\right)$ e percentual da variância acumulada por meio da rotação normalizada Varimax.

\begin{tabular}{|l|l|l|l|}
\hline Componentes Principais & $(\Lambda)$ & $\left(\sigma^{2 \%}\right)$ & $\%$ Variância Acumulada \\
\hline CP1 & 5,37 & 67,14 & 67,14 \\
\hline CP2 & 1,24 & 15,58 & 82,73 \\
\hline CP3 & 0,58 & 7,28 & 90,01 \\
\hline CP4 & 0,49 & 6,20 & 96,22 \\
\hline CP5 & 0,17 & 2,17 & 98,39 \\
\hline CP6 & 0,10 & 1,34 & 99,73 \\
\hline CP7 & 0,01 & 0,21 & 99,95 \\
\hline CP8 & 0,003 & 0,04 & 100,00 \\
\hline
\end{tabular}

$\mathrm{CP}=$ componente principal; $\Lambda$ = Autovalores; $\sigma^{2} \%=$ Variância Total.

Nota-se ainda a partir da projeção dos escores fatoriais dos dois primeiros CPs em duas dimensões, constatou-se que 67,14\% da variância deve-se à variação temporal representada pelos níveis de salinidade. No CP2, é possível observar que $15,58 \%$ da variância deve-se aos tipos de adubação utilizados (com e sem húmus de minhoca).

Andrade et al. (2017) ao estudar a aplicação da estatística multivariada na identificação das características biométricas de produção e qualidade de frutos do melão verificaram que dentre as 11 componentes principais geradas, apenas duas responderam por uma proporção significativa de $63,69 \%$ da variância acumulada total das variáveis originais e autovalores com valores superiores a 1. Resultados estes bem similares aos obtidos neste estudo embora com espécies diferentes. 
A matriz de correlação (Anti-imagem Correlation), indica o poder de explicação dos fatores em cada uma das variáveis analisadas (Tabela 4). Corrar et al. (2009) afirmam que a diagonal da matriz (Anti-imagem Correlation) apresenta a análise do sistema de medição (MAS) de cada variável analisada e os valores superiores a 0,50 são considerados adequado aos pressupostos da utilização da análise fatorial (AF) e de componentes principais (ACP).

Tabela 4: Matriz de correlações para as variáveis de crescimento e qualidade da raiz de cenoura sob níveis de salinidade da água de irrigação e tipos de adubação.

\begin{tabular}{|c|c|c|c|c|c|c|c|c|}
\hline & $\mathrm{AP}$ & $\mathrm{NF}$ & $\mathrm{AF}$ & DSR & DIR & MFR & MSR & ${ }^{\circ} \mathrm{BRIX}$ \\
\hline AP & 1,00 & $0,79 *$ & $0,85^{*}$ & $0,85^{*}$ & 0,44 & $0,80^{*}$ & 0,46 & $0,55^{*}$ \\
\hline $\mathrm{NF}$ & & 1,00 & $0,70^{*}$ & $0,79 *$ & 0,25 & $0,79 *$ & $0,58^{*}$ & $0,51^{*}$ \\
\hline $\mathrm{AF}$ & & & 1,00 & $0,68^{*}$ & $0,50 *$ & $0,68^{*}$ & 0,32 & $0,66^{*}$ \\
\hline DSR & & & & 1,00 & $0,57^{*}$ & $0,91^{*}$ & $0,63^{*}$ & $0,64^{*}$ \\
\hline DIR & & & & & 1,00 & 0,40 & $-0,07$ & 0,25 \\
\hline MFR & & & & & & 1,00 & $0,82^{*}$ & $0,69 *$ \\
\hline MSR & & & & & & & 1,00 & $0,69 *$ \\
\hline${ }^{\circ} \mathrm{BRIX}$ & & & & & & & & 1,00 \\
\hline
\end{tabular}

* correlação superior a 0,5

Verifica-se todas as variáveis apresentam correlação superior a 0,5 com pelo menos uma das outras variáveis de qualidade agronômica de raízes de cenoura (Tabela 4). Com base nos dados obtidos pela matriz de correlações é possível classificar as correlações com base na recomendação de Dancey et al. (2013), onde as correlações, $r=|0,10|$ até $|0,30|$ (fraca); $r=|0,40|$ até $|0,6|$ (moderada); $r=|0,70|$ até $|1,00|$ (forte). Constata-se correlação muito forte e positiva entre as variáveis altura de plantas (AP) e área foliar (AF) ( $r=$ 0,85), altura de plantas (AP) e diâmetro superior da raiz (DSR) $(r=0,85)$ e diâmetro superior da raiz (DSR) e massa fresca da raiz (MFR) $(r=0,91)$. As correlações muito fortes entre as variáveis de crescimento e as de qualidade das raízes são esperadas, uma vez que estão correlacionadas, com a produção de fotoassimilados e produtividade das plantas.

No primeiro fator CP1 as variáveis AP, NF, DSR, MFR, MSR e ${ }^{\circ}$ Brix, apresentaram peso superior a 0,75, indicando que essas variáveis são as mais significativas na definição da qualidade das raízes de cenoura sob diferentes níveis de salinidade da água de irrigação e tipos de adubação (Tabela 5).

Tabela 5: Matriz de peso fatorial das variáveis da qualidade agronômica das raízes de cenoura submetidas a diferentes níveis de salinidade da água de irrigação e tipos de adubação nos dois componentes principais selecionados

\begin{tabular}{|l|l|l|}
\hline Variável & CP1 & CP2 \\
\hline AP & $-0,83$ & 0,50 \\
\hline NF & $-0,94$ & 0,13 \\
\hline AF & $-0,25$ & 0,79 \\
\hline DSR & $-0,93$ & 0,18 \\
\hline DIR & 0,28 & 0,81 \\
\hline MFR & $-0,97$ & $-0,09$ \\
\hline MSR & $-0,83$ & $-0,51$ \\
\hline${ }^{\circ}$ BRIX & $-0,77$ & $-0,21$ \\
\hline
\end{tabular}

$\mathrm{CP}-$ Componente principal.

Os fatores que possuem peso superior a 0,75 são indicativos de forte carga entre as variáveis da qualidade agronômica de raízes de cenoura e os níveis de salinidade da água aplicados via irrigação; assim, 
este fator representa o indicativo do efeito do nível salino sobre estas variáveis de qualidade agronômica (Tabela 5).

Luz et al. (2009) estudaram diferentes níveis de salinidade na cultura da cenoura cv. Brasília, e obtiveram, que as variáveis de crescimento e qualidade de raiz foram as mais influenciada quando submetidos a tratamentos salinos superiores a $0,1 \mathrm{dS} \mathrm{m}^{-1}$, neste estudo os níveis salinos foram bem superiores em função disto pode ter ocorrido maiores efeitos. Resultados semelhantes obtiveram Medeiros et al. (2012) e Melo et al. (2011) para tomate e meloeiro.

O segundo fator é explicado pelas variáveis: área foliar a (AF) e Diâmetro inferior da raiz (DIR), os quais indicam que a adubação com húmus de minhoca pode ter contribuído para atenuar o efeito da irrigação com água salina (Tabela 5). Melo et al. (2011) também constataram, avaliando a interação entre salinidade e adubação nitrogenada na cultura do meloeiro, que a adubação nitrogenada pode ser um atenuante do efeito dos níveis mais elevados de salinidade nas plantas.

O resultado da correlação entre a combinação das variáveis analisadas e dos tratamentos (Salinidade $=$ S) e (tipos de adubação $=A$ ) com os escores das duas componentes principais geradas pela análise fatorial (CP1 e CP2), que respondem por $82,73 \%$ da variabilidade acumulada encontra-se na (Figura 2A). Observam-se como as variáveis e os tratamentos agrupam-se e como são suas relações com os eixos (OXY), com as cargas fatoriais e com as componentes principais (CP1 e CP2) através das técnicas da AF e ACP (Figura 2A).

A

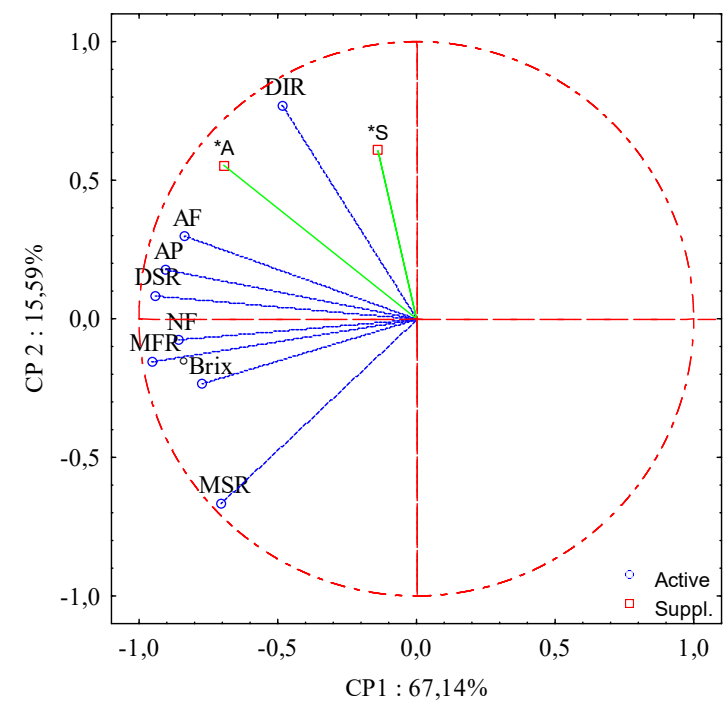

B

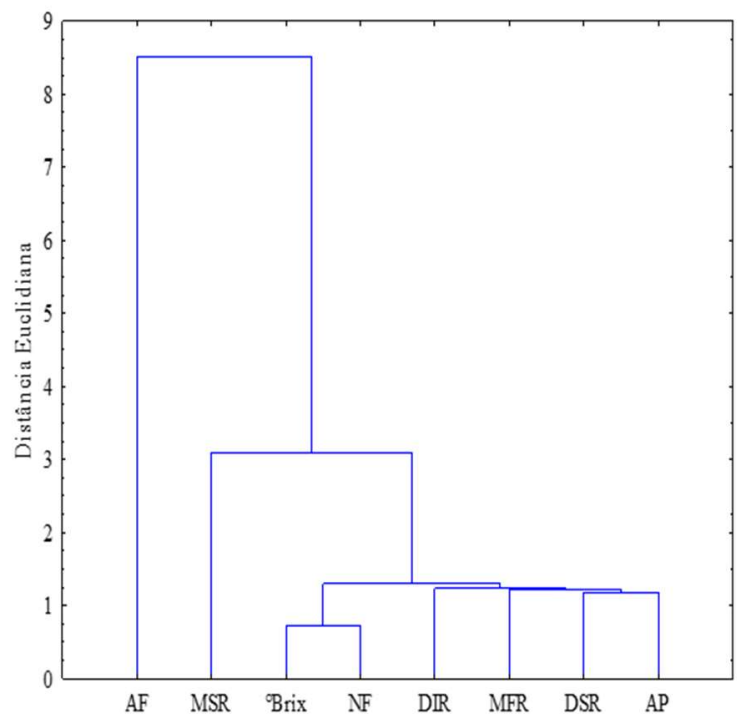

Figura 2: Biplot contendo as variáveis estudadas da qualidade agronômica das raízes de cenoura em função dos níveis de salinidade e tipos de adubação para os competentes CP1 e CP2 (A) e dendograma dos métodos de agrupamento hierárquicos a partir da distância euclidiana média (B).

A correlação das 8 variáveis de crescimento, produção e qualidade da cenoura e dos tratamentos com os escores das duas componentes principais geradas pela análise fatorial (CP1 e CP2), evidenciam que estas variáveis analisadas e os tratamentos formam grupos por similaridades de explicação, ou seja, estão agrupadas por componentes (CP) (Figura 2A). As variáveis que melhor representam a CP1 formam grupo distinto das demais, e são representadas pelas variáveis: ${ }^{\circ}$ Brix, NF, MFR e MSR, estando localizadas distantes 
da origem dos eixos $X Y$, denominado de plano fatorial, sendo estas que possuem uma maior representatividade na $\mathrm{CP} 1$ (Figura $2 \mathrm{~A}$ ).

E as variáveis que melhor representam a CP2, formam o segundo grupo distinto, e são representadas pelas variáveis: DSR, DIR, AP, AF, salinidade (S) e Tipos de adubação (A) estando localizadas distantes da origem dos eixos (Figura 2A). Outro fato importante, é que algumas variáveis estão bem próximas ao círculo unitário, indicando que estas possuem uma maior contribuição, em relação as variáveis que estão mais afastadas (DIR, DSR, MFR e MSR). Estes resultados corroboram com os obtidos para a cultura do melão (ANDRADE et al., 2017).

A análise de agrupamento hierárquico ou de cluster $(\mathrm{AHH})$ a partir das distancias euclidiana proporcionou a formação de quatro grupos (Figura 2B). O primeiro formado pela área foliar (AF), o segundo pela massa seca de raiz (MSR), o terceiro pelo ${ }^{\circ}$ Brix e o número de folhas (NF). Por fim o quarto grupo formado pelo diamêtro inferior da raiz (DIR), massa fresca da raiz (MSR), diamêtro superior das raízes (DSR) e altura de plantas (AP).

Verifica-se que o ponto ótimo formação dos grupos de similaridade se encontra aproximadamente no ponto 1 da distância euclidiana, pois, a partir deste, ocorre o distanciamento maior na medida de similaridade para a formação dos grupos (Figura 2B). Percebe-se que os grupos 1 e 3 foram os de maior representatividade, pela CP1 com 46,93\%. Os grupos 2 e 4 foram os de menor representatividade pela CP2 (16,19\%). Esta similaridade do plano fatorial permite confirmar se as variáveis que estão no mesmo grupo são as mesmas que explicam determinada $\mathrm{CP}$, confirmando com o que preconiza (RANAMUKHAARACHCHI et al., 2017; Yl et al., 2017).

\section{CONCLUSÕES}

O uso das técnicas de multivariadas mostrou-se uma ferramenta útil no estudo entre as correlações dos diferentes níveis de salinidade da água de irrigação e os tipos de adubação, a fim de verificar o efeito na qualidade agronômica de cenoura. $\mathrm{O}$ nível de salinidade de $0,7 \mathrm{dSm}^{-1}$ associada a adubação com húmus de minhoca favoreceu a qualidade agronômica das raízes de cenoura. $O$ efeito da salinidade nos níveis elevados foi atenuado pela adubação orgânica com húmus de minhoca.

AGRADECIMENTOS: Agradecimentos a CAPES e o CNPq pela concessão de bolsa de estudos.

\section{REFERÊNCIAS}

ANDRADE, A. R. S.; CRUZ, A. F. S.; BEZERRA, T. M. E.; LIMA, J. R. S.. Aplicação da estatística multivariada na identificação das características biométricas de produção e qualidade de frutos do melão. Brazilian Journal of Applied Technology for Agricultural Science, v.10, n.1, p.25-40, 2017. DOI: http://dx.doi.org/10.5935/PAeT

AYERS, R. S.; WESTCOT, D. W.. A qualidade da água na agricultura. Campina Grande: UFPB, 1991.
BERTOLLI, S. C.; SOUZA, J.; SOUZA, G. M.. Caracterização fotossintética da espécie isohídrica pata-de-elefante em condições de deficiência hídrica. Revista Caatinga, Mossoró, v.28, p.196-205, 2015. DOI: http://dx.doi.org/10.1590/198321252015v28n322rc

CORRAR, L. J.; PAULO, E.; DIAS FILHO, J. M.. Análise multivariada: para cursos de administração, ciências contábeis e economia. São Paulo: Atlas, 2009. 
DANCEY, C.; REIDY, J.. Estatística Sem Matemática para

Psicologia. Porto Alegre: Artmed, 2013.

DIAS, N. S.; BLANCO, F. F.; SOUZA, E. R.; FERREIRA, J. F.; SOUSA NETO, O. N.; QUEIROZ, I. S. R.. Efeitos dos sais na planta e tolerância das culturas à salinidade. In: GHEYI, H. R.; DIAS, N. S.; LACERDA, C. F.; GOMES FILHO, E.. Manejo da salinidade na agricultura: Estudo básico e aplicados. 2 ed. Fortaleza: INCTSal, 2016. p.151-161.

HAIR, F. J.; BLACK, W. C.; BABIN, B. J.; ANDERSON, R. E.; TATHAM, R. L.. Análise Multivariada de Dados. Porto Alegre: Bookman, 2009.

KRÄHMER, A.; BÖTTCHER, C.; RODE, A.; NOTHNAGEL, T.; SCHULZ, H.. Quantifying biochemical quality parameters in carrots (Daucus carota L.) - FT-Raman spectroscopy as efficient tool for rapid metabolite profiling. Food Chemistry, v.212, n.1, p.495-502, 2016. DOI:

http://dx.doi.org/10.1016/j.foodchem.2016.05.176

MEDEIROS, P. R. F.; DUARTE, S. N.; UYEDA, C. A.; SILVA, E. F. F.; MEDEIROS, J. F.. Tolerância da cultura do tomate à salinidade do solo em ambiente protegido. Revista Brasileira de Engenharia Agrícola e Ambiental, Campina grande, v.16, n.1, p.51-55, 2012. DOI: http://dx.doi.org/10.1590/S1415$\underline{43662012000100007}$

MELO, T. K.; MEDEIROS, J. F.; ESPÍNOLA SOBRINHO, E.; FIGUEIRÊDO, V. B.; PEREIRA, V. C.; CAMPOS, M. S.. Evapotranspiração e produção do melão Gália irrigado com água de diferentes salinidades e adubação nitrogenada. Revista Brasileira de Engenharia Agrícola e Ambiental, Campina Grande, v.15, n.12, p.1235-1242, 2011. DOI: http://dx.doi.org/10.1590/S1415-43662011001200004

NETO, F. B.; OLIVEIRA, L. J; SANTOS, A. P; LIMA, J. S. S.; SILVA, I. N.. Otimização agroeconômica da cenoura fertilizada com diferentes doses de jitirana. Revista Ciência Agronômica, Fortaleza, v.45, n.2, p.305-311, 2014.

NOBRE, R. G.; GHEYI, H. R.; SOARES, F. A. L.; CARDOSO, J. A. F.. Produção de girassol sob estresse salino e adubação nitrogenada. Revista Brasileira de Ciência do Solo, Visçosa, v.35, p.929-937, 2011.
OLIVEIRA, F. A.; MEDEIROS, J. F.; CUNHA, R. C.; SOUZA, M. W. L.; LIMA, L. A.. Uso de bioestimulante como agente amenizador do estresse salino na cultura do milho pipoca. Revista Ciência Agronômica, Fortaleza, v.47, p.307-315, 2016.

LUZ, J. M. Q; SILVA JÚNIOR, J. A.; TEIXEIRA, M. S. S. C.; SILVA, M. A. D.; S. G. M.; MELO, B.. Desempenho de cultivares de cenoura no verão e outono-inverno em Uberlândia-MG. Horticultura Brasileira, Brasília, v.27, n.1, p.96-99, 2009 DOI: http://dx.doi.org/10.1590/S0102-05362009000100019

PEREIRA, D. C.; WILSEN NETO, A.; NÓBREGA, L. H. P. Adubação orgânica e algumas aplicações agrícolas. Varia Scientia Agrárias, Cascavel, v.3, n.2, p.159-174, 2013.

RANAMUKHAARACHCHI, S. A.; PEIRIS, R. H.; MORESOLI, C.. Fluorescence spectroscopy and principal component analysis of soyprotein hydrolysate fractions and the potential to assess theirantioxidant capacity characteristics. Food Chemistry, v.217, n.1, p.469-475, 2017. DOI: http://doi.org/10.1016/i.foodchem.2016.08.029

STATSOFT, I. STATISTICA (data analysis software system), version 7. 2004

STORCK, C. R.; NUNES, G. L; OLIVEIRA, B.; BASSO, C.. Folhas, talos, cascas e sementes de vegetais: composição nutricional, aproveitamento na alimentação e análise sensorial de preparações. Ciência Rural, Santa Maria, v.43, n.3, p.537-543, 2013. DOI: http://dx.doi.org/10.1590/S010384782013000300027

TEIXEIRA, L. J. Q.; POLA, C. C.; JUNQUEIRA, M. S.; MENDES, F. Q.; RODRIGUES JUNIOR, S. R.. Cenoura (Daucus carota): processamento e composição química. Enciclopédia Biosfera, Goiania, v.7, n.12, p.1-21, 2011.

YI, S.; LAI, Z.; HE, Z.; CHEUNG, Y.; LIU, Y.. Joint sparse principal component analysis. Pattern Recognition, v.61, n.1, p.524-536, 2017. DOI: http://doi.org/10.1016/j.patcog.2016.08.025

A CBPC - Companhia Brasileira de Produção Científica (CNPJ: 11.221.422/0001-03) detém os direitos materiais desta publicação. Os direitos referem-se à publicação do trabalho em qualquer parte do mundo, incluindo os direitos às renovações, expansões e disseminações da contribuição, bem como outros direitos subsidiários. Todos os trabalhos publicados eletronicamente poderão posteriormente ser publicados em coletâneas impressas sob coordenação da Sustenere Publishing, da Companhia Brasileira de Produção Científica e seus parceiros autorizados. Os (as) autores (as) preservam os direitos autorais, mas não têm permissão para a publicação da contribuição em outro meio, impresso ou digital, em português ou em tradução. 